\title{
Evaluation of a thyroid nodule
}

\author{
Steven R. Bomeli, MD1 ${ }^{1}$, Shane O. LeBeau, MD², and Robert L Ferris, MD, PhD ${ }^{1}$ \\ ${ }^{1}$ University of Pittsburgh, Department of Otolaryngology, Head \& Neck Surgery, Pittsburgh, PA \\ 2 University of Pittsburgh, Division of Endocrinology and Metabolism, Pittsburgh, PA
}

\begin{abstract}
The thyroid specialist frequently evaluates thyroid nodules because they may represent malignancy. Nodules are typically found on physical exam or incidentally when other imaging studies are performed. Malignant or symptomatic nodules that compress nearby structures warrant surgical excision. Yet, the majority of thyroid nodules are asymptomatic and benign, so the thyroid surgeon must rely on diagnostic studies to determine when surgery is indicated. Ultrasound is the preferred imaging modality for thyroid nodules, and the ultrasound guided fine needle aspiration biopsy (FNAB) is the preferred method of tissue sampling. Nodules one centimeter or larger, or nodules with suspicious sonographic appearance warrant cytologic analysis to better quantify the risk of malignancy. Molecular biomarkers are a powerful adjunct to cytology, as detecting malignancy preoperatively allows total thyroidectomy in a single operation without the need for frozen section or a second operation for completion thyroidectomy if malignancy is found during the initial thyroid lobectomy.
\end{abstract}

\section{Keywords}

Thyroid nodule; Thyroidectomy; BRAF; RAS; Papillary; Follicular; Fine-needle aspiration biopsy; Thyroid cancer; Molecular markers

\section{Introduction}

The thyroid nodule is a common entity. While autopsy data indicate a $50 \%$ prevalence of thyroid nodules larger than one centimeter in patients without clinical evidence of thyroid disease, the prevalence of palpable nodules is only 4 to $7 \%,(1,2)$. Ultrasonography is far more sensitive than palpation, as it detects nodules of any size in up to $67 \%$ of the general population (3). Thyroid nodules warrant removal when they are large enough to be symptomatic, or if there is a concern for malignancy. The majority of nodules are asymptomatic, and with only 5 to $10 \%$ of nodules being malignant, the decision to operate is made on therapeutic or diagnostic grounds $(4,5)$. Ultrasound imaging studies and cytology from fine-needle aspiration are the main tools used by the clinician to decide whether surgical excision of a thyroid nodule is

\footnotetext{
(c) 2009 Elsevier Inc. All rights reserved.

Corresponding Author: Robert L. Ferris, MD, PhD Eye \& Ear Institute, Suite 500203 Lothrop Street Pittsburgh, PA 15213 ferrrl@upmc.edu Robert L. Ferris, M.D., Ph.D. Associate Professor Vice-Chair for Clinical Operations Chief, Division of Head and Neck Surgery Departments of Otolaryngology and of Immunology Co-Leader, Cancer Immunology Program University of Pittsburgh Cancer Institute Phone: (412) 623-0327 (Karen Seisek) Fax: (412) 623-4840

DISCLOSURES: Conflict of interest: None. Source of Funding: None

Publisher's Disclaimer: This is a PDF file of an unedited manuscript that has been accepted for publication. As a service to our customers we are providing this early version of the manuscript. The manuscript will undergo copyediting, typesetting, and review of the resulting proof before it is published in its final citable form. Please note that during the production process errors may be discovered which could affect the content, and all legal disclaimers that apply to the journal pertain.
} 
warranted. Molecular genetic biomarker analyses are now being used to increase the accuracy of fine needle aspiration biopsies, and appear to substantially alter the clinical decision-making process as they become more widely available and more thoroughly evaluated.

\section{Clinical assessment}

Patients most often present with a large palpable nodule in the neck or report of an incidental nodule found on imaging studies performed for another reason. A single dominant or solitary nodule is more likely to represent carcinoma than a single nodule within a multinodular gland, with an incidence of malignancy from 2.7 to $30 \%$ and 1.4 to $10 \%$ respectively (6). Yet, the overall risk of malignancy within a gland with a solitary nodule is approximately equal to that of a multinodular gland due to the additive risk of each nodule (7). Important elements in the patient's history which increase the likelihood of malignancy include prior head and neck irradiation (especially during childhood, with a relative risk of 8.7 at $1 \mathrm{~Gy}$ for x-rays and gamma-radiation), reports of rapid growth, dysphagia, dysphonia, male gender, presentation at extremes of age (less than 20 years or more than 70 years), and a family history of medullary thyroid carcinoma or multiple endocrine neoplasia $(8,9)$.

Physical exam findings that increase the concern for malignancy include:

- Nodules larger than $4 \mathrm{~cm}$ in size (19.3\% risk of malignancy (10))

- Firmness to palpation

- Fixation of the nodule to adjacent tissues

- Cervical lymphadenopathy

- Vocal fold immobility

Physical exam may be limited by the patient's body habitus, as well as an inherent variation between physicians and their assessment of nodules such that more precise measurements are obtained through imaging (11). Positive predictive values of $100 \%$ for thyroid malignancy in the setting of a nodule have been reported for the physical exam findings of cervical lymphadenopathy (greater than $1 \mathrm{~cm}$ ) and vocal fold immobility (12). Assessment of a patient's voice is not adequately sensitive at detecting vocal fold immobility when compared to flexible laryngoscopy (13). A thorough head and neck exam with visualization of vocal fold movement is therefore of utmost importance on initial presentation.

\section{Laboratory studies}

Most patients presenting with a solitary thyroid nodule are euthyroid, and the simplest way to verify this is a serum thyrotropin (TSH) level. If below normal, the workup proceeds with total or free thyroxine (T4) and total triiodothyronine (T3) to better evaluate the hyperthyroid state. This occurs in approximately $10 \%$ of patients with a solitary thyroid nodule and is suggestive of a benign hyperfunctioning adenoma (14). Serum calcitonin levels should be obtained in any patient with a family history of medullary thyroid carcinoma, multiple endocrine neoplasia types $2 \mathrm{a}$ or $\mathrm{b}$, pheochromocytoma, or hyperparathyroidism. As only 1 in 250 nodules represents medullary thyroid carcinoma, serum calcitonin testing is reserved for high risk patients (15). Furthermore, calcitonin levels alone are unable to distinguish between benign and malignant disease (16). 


\section{Imaging studies}

\section{Ultrasonography}

Ultrasonography is the imaging study of choice for thyroid nodules. It can identify nodules too small to be palpated, the presence of multiple nodules, central, or lateral neck lymphadenopathy, and provides accurate measurements of nodule diameter for interval monitoring. Additionally, it allows characterization of nodules by sonographic features which suggest malignancy. Solid appearance (or hypoechogenicity), increased vascularity, microcalcifications, irregular margins, and the absence of a halo are features that have been consistently associated with malignancy (Table 1$)(4,17)$. There is certainly some subjectivity to these features, and characteristics vary depending on the histology such that ultrasound alone cannot reliably distinguish malignant and benign lesions (18). While they do not obviate the need for biopsy, these features are extremely useful in selecting the site within a nodule for fine needle aspirate biopsy (FNAB) in order to improve diagnostic yield, or to select appropriate nodules to aspirate within a multinodular thyroid (4).

\section{Radioisotope imaging}

Radioisotope scanning can be used to determine if a thyroid nodule is functioning, but it does not provide an accurate measurement of size. Radioisotopes that have been used are technetium $\left({ }^{99 \mathrm{~m}} \mathrm{Tc}\right),{ }^{123} \mathrm{I}$, and ${ }^{131} \mathrm{I}$, and though similar information is obtained with similar amounts of radiation exposure, radioiodine is preferred (19). About 80 to $85 \%$ of thyroid nodules are cold, and about $10 \%$ of these nodules represent a malignancy. Hot nodules account for $5 \%$ of all nodules, and the likelihood of malignancy is less than $1 \%$ for these nodules. Taken together, the sensitivity for the diagnosis of thyroid cancer is 89 to $93 \%$, specificity is $5 \%$, and the positive predictive value of malignancy is only $10 \%$ (20). Except for obviating the need to perform an FNAB on a hyperfunctioning nodule in a thyrotoxic patient, the use of radioisotope scanning has been nearly abandoned in the initial workup of a thyroid nodule.

\section{Computed tomography (CT) and magnetic resonance imaging (MRI)}

Both of these imaging modalities have almost no role in the initial evaluation of a thyroid nodule, and are rarely indicated in the initial workup. However, they are both excellent (100\% sensitivities) for evaluating the extent of large substernal goiters which may be compressing nearby structures (21). Of note, iodinated contrast material utilized for CT scan should be avoided because its use prevents scintigraphy or administration of radioactive iodine (RAI) therapy for a period of 1 to 2 months. Gadolinium contrast used with MRI does not interfere with thyroid uptake of radiotracer, but it is significantly more expensive than CT or ultrasound.

\section{${ }^{18} \mathrm{~F}$-fluorodeoxyglucose positron emission tomography-computed tomography $\left({ }^{18} \mathrm{FDG}-\mathrm{PET} /\right.$ CT)}

${ }^{18}$ FDG-PET/CT is used extensively in oncology for staging, evaluation of treatment response, and detecting recurrences on the principle that malignant cells have a higher uptake of ${ }^{18}$ FDG due to increased metabolic demands when compared to normal tissues (22). Generally, the appearance of the images and maximum standard uptake value $\left(\mathrm{SUV}_{\max }\right)$ can be used to distinguish between malignant and benign lesions. This does not appear to be the case with thyroid nodules, as there is no significant difference in $\mathrm{SUV}_{\max }$ between benign and malignant ${ }^{18}$ FDG-avid nodules (23). Some have suggested that ${ }^{18}$ FDG-PET/CT may play a role in reducing the need for diagnostic thyroid lobectomy for FNAB indeterminate lesions because it has negative predictive values 95 to $100 \%(24,25)$. While such preliminary studies are promising, further research is needed before observation could universally be recommended over surgery for non- ${ }^{18}$ FDG-avid thyroid nodules with indeterminate FNA cytology. Although ${ }^{18}$ FDG-PET/CT does not play a role in the workup of a nodule, 
any ${ }^{18}$ FDG-avid thyroid nodule found incidentally deserves a thorough workup for malignancy (26).

\section{Fine-needle aspiration biopsy}

Fine needle aspiration biopsy (FNAB) is the most important step in the workup of the thyroid nodule, as cytology is the primary determinant in whether thyroidectomy is indicated. FNAB is widely available and well tolerated, with a low risk of complications. Its use has dramatically decreased the number of thyroidectomies performed, and improved the yield of malignancy in glands that have been extirpated (27). FNAB can be performed with or without ultrasound guidance, but diagnostic accuracy is improved using sonographic needle localization due to a decreased number of inadequate specimens and false negative results (28).

The pathology report from FNAB may be read as benign, malignant, indeterminate, or nondiagnostic. The exact terminology may vary between institutions as there is currently no standard means of reporting FNAB cytology specimens, especially with regard to indeterminate specimens. The latest proposal from the National Cancer Institute (NCI) is that cytology should universally be reported under six categories which more accurately predict the risk of malignancy (Table 2) (29). Benign lesions on FNAB have an approximate 3\% risk of malignancy (although this will vary with patient population), and may be followed clinically with ultrasound or with a repeat FNAB which, if also benign, decreases the risk of a false negative to $1.3 \%(30)$.

The only malignant pathology reliably diagnosed through fine needle aspiration is papillary thyroid carcinoma, as features such as 'Orphan Annie' nuclei, nuclear grooves, intra-nuclear inclusions, and psammoma bodies can be sufficient for a diagnosis. Medullary carcinoma, anaplastic carcinoma, lymphoma, poorly differentiated carcinoma, and metastatic disease have also been reported to be classified on the basis of cytology (29). Benign and malignant follicular neoplasms and oncocytic (formerly called Hurthle cell) adenomas and carcinomas cannot be distinguished on the basis of cytology alone, as tissue architecture is required to make the diagnosis of malignancy through observation of capsular or angiolymphatic invasion. While this has historically been true, recent advances in the application of molecular markers to FNAB are changing these principles.

\section{Molecular markers in fine-needle aspiration biopsy}

Although still early in clinical application, the use of genetic biomarkers to assist in interpretation of FNAB samples is likely to greatly enhance the ability to distinguish benign from malignant thyroid nodules in conjunction with cytology. The current algorithms for the extent of thyroid surgery based upon these results are evolving. This stands in distinct contrast to immunohistochemical staining techniques such as HBME-1, galectin-3, cytokeratin, which may assist with indeterminate FNAB specimens, but truthfully have not dramatically changed clinical practice due to difficulties with the amount of tissue needed and subjective interpretation of stains (31).

Genetic mutations implicated in the development of differentiated thyroid carcinoma alter the DNA sequence encoding tyrosine kinase receptors (RET/PTC, NTRK), nuclear proteins (PAX-8-PPAR $\gamma$ ), and signaling proteins (RAS, BRAF). RET/PTC rearrangements occur only in papillary thyroid carcinoma, but NTRK and BRAF mutations are also common. Greater than $70 \%$ of papillary thyroid carcinomas will have mutations in the BRAF, RAS, or RET/PTC genes (32). The BRAF V600E mutation is associated with more aggressive forms of papillary carcinoma $(33,34)$. The mutations in the RAS proto-oncogenes (HRAS, NRAS, KRAS) or PAX-8-PPAR $\gamma$ rearrangement are found in approximately $70 \%$ of follicular carcinomas (35). Finding the BRAF mutation, RET/PTC, or PAX-8-PPAR $\gamma$ rearrangements in an indeterminate 
FNAB specimen has been correlated with a $100 \%$ specificity of thyroid cancer in a recent prospective study, and RAS mutation similarly correlated with a $83-87 \%$ risk of malignancy in any FNAB sample (36). A false-positive BRAF mutation has been described and the RET/ PTC rearrangement can be found in benign conditions such as trabecular adenoma and Hashimoto thyroiditis, so all clinical and cytologic data must be interpreted in addition to mutation analyses $(37,38)$. BRAF and RAS are currently the most widely prevalent and studied mutations utilized for making clinical decisions. Although preliminary data for RET/PTC and PAX-8-PPAR $\gamma$ mutations appears promising, the numbers of published cases are too sparse to assist with clinical decisions at the present time $(36,39)$. Although the exact indications for mutation analysis are under investigation, it appears that most clinical utility lies in aiding to make the decision between thyroid lobectomy and total thyroidectomy when the cytology is characterized as follicular neoplasm or suspicious for malignancy. Treatment algorithms will change as more data accumulates and these assays become more widely available.

\section{Nodule size}

Sampling error of a FNAB increases as the size of a thyroid nodule increases. A $17 \%$ false negative rate for solid thyroid nodules $3 \mathrm{~cm}$ or larger in size and a $30 \%$ false negative rate for cystic nodules $3 \mathrm{~cm}$ or larger led to a recommendation of diagnostic lobectomy for any nodule $3 \mathrm{~cm}$ or larger in size (40). More recent research has reported that this measurement may be increased to $4 \mathrm{~cm}$ with the increased diagnostic yield of modern ultrasound guidance for FNAB. The rate of cancer for $4 \mathrm{~cm}$ nodules is $19 \%$ with a false negative rate for FNAB of $12.7 \%$ (10). Recommendations of surgery based on size alone are controversial, but the patient's risk factors and concerns often guide the management of nodules this large. The age of the patient must also be considered, as a definitive lobectomy is often preferred to multiple FNABs required to follow a nodule in a younger patient. A single preoperative FNAB is still useful in nodules 3 to $4 \mathrm{~cm}$ in diameter that are destined for surgical excision, because a malignant biopsy allows planning for total thyroidectomy without the need for frozen section analysis.

\section{Frozen section analysis}

For FNAB indeterminate specimens, a diagnostic thyroid lobectomy is often performed with intra-operative frozen section analysis in order to prevent a return trip to the operating room for completion thyroidectomy. There is certainly variation in the confidence at which a pathologist will read a frozen section, as the result will be deferred in any instances of uncertainty. The true utility of this practice has long been debated. Proponents for routine use of intraoperative frozen section have demonstrated cost effectiveness and a reduced number of completion thyroidectomies when it is utilized for follicular lesions (41). Others disagree on the basis that increased costs from additional operating time and pathologists needed to read the specimens are not justified by a significant benefit in patient outcomes (42). Frozen section analysis often complements the fine needle aspiration cytology in cases with cytologic atypia or suspicious appearance, and is most useful at making a diagnosis of papillary thyroid carcinoma (43). Its efficacy and therefore use will vary between institutions, surgeons, and pathologists.

\section{Workup and Surgical Recommendations}

We have proposed the algorithm in Figure 1 for the thyroid surgeon's workup of a thyroid nodule. It is based upon the 2006 ATA guidelines for the workup of a thyroid nodule with incorporation of mutational analysis (44). One indication for surgery is whether the nodule is symptomatic due to compression of nearby structures. These patients are typically evaluated with CT or MRI and loop spirometry, and a lobectomy is typically performed to remove the compressive lesion. In rare instances, a total thyroidectomy is indicated if both lobes of the thyroid are problematic. Any asymptomatic thyroid nodule should be evaluated with a 
diagnostic ultrasound and a TSH level. Often times, these tests have been completed prior to a patient's arrival in the surgeon's office. Nodules smaller than $1 \mathrm{~cm}$ in diameter should be followed with a yearly ultrasound, with FNAB indicated for any concerning changes in appearance or growth. A biopsy of subcentimeter nodules may be indicated if there is a significant history of radiation exposure, a strong family history of thyroid carcinoma, or worrisome sonographic features.

A subnormal TSH level increases suspicion for a hyper-functioning nodule, and only in this circumstance should a thyroid uptake scan be ordered. If the nodule is "hot," the patient can be managed by their endocrinologist without further workup as there is a less than $1 \%$ risk of malignancy (20). This situation is rather rare in the clinical practice of a thyroid surgeon, as the majority of patients with nodules are euthyroid and a patient with hyperthyroidism is typically referred to the endocrinologist's office for medical management.

Unless easily palpable, an ultrasound guided FNAB is the first diagnostic step for an asymptomatic thyroid nodule with a diameter of $1 \mathrm{~cm}$ or larger in a euthyroid patient. Even if the nodule is symptomatic or in the $4 \mathrm{~cm}$ size range which alone warrants surgical excision, an FNAB is recommended as it may preoperatively determine whether a total thyroidectomy is to be performed over a lobectomy. FNAB cytology will return as unsatisfactory, benign, intermediate, or malignant.

The intermediate group has been subclassified into follicular lesion of undetermined significance (FLUS), follicular neoplasm, or suspicious for malignancy according to the 2007 Bethesda thyroid cytology classification from the National Cancer Institute (29).

FNAB specimens read as unsatisfactory should be sent for a repeat biopsy so that useful diagnostic information may be obtained. Samples read as FLUS are generally sent for repeat FNAB, as the risk of malignancy is only 5 to $10 \%$. Yet, if the FLUS sample is positive for BRAF or RAS mutations, unpublished data from over 900 cases at the University of Pittsburgh Medical Center suggests that a total thyroidectomy is indicated (Nikiforov, Y, et al, unpublished data). The portion of Figure 1 designated with an asterisk (*) reflects this practice, but it is not fully validated or universally accepted at this point in time.

Benign lesions can safely be followed with yearly ultrasound examination, with a repeat FNA with any increase in size or development of concerning sonographic features. Efforts to shrink the size of a benign nodule with TSH suppression are not generally useful (44).

A malignant lesion identified by FNAB is an indication for total thyroidectomy, and ultrasonography should assess central or lateral nodal status.

Patients with lesions classified as follicular or oncocytic neoplasm, or suspicious for malignancy should be offered a diagnostic lobectomy in situations where molecular testing is not available. Where diagnostic testing with BRAF and RAS mutations is available, finding one of these mutations in an indeterminate FNA specimen predicts malignancy with a 100\% specificity and positive predictive value according to a recent prospective study (36). A 100\% specificity for BRAF has been confirmed by a second prospective study (39). Finding one of these mutations in an indeterminate FNA specimen may be considered an indication for total thyroidectomy in some medical centers. Caution is advised, as a false positive BRAF mutation has been described. In this case, the final pathology was of atypical nodular hyperplasia which may be a premalignant lesion (37). Surgical excision of any RAS mutated cytology specimen in the form of lobectomy regardless of cytopathology must also be considered as it has an $87.5 \%$ risk of malignancy (36). Even when histologically benign, RAS-positive follicular adenomas are likely precursors to follicular carcinoma (35). The use of molecular testing is unlikely to be routinely performed on all FNA specimens due to cost, but their role in the 
indeterminate FNA appears to be invaluable. Further clinical studies are required to determine the cytology and imaging characteristics of nodules where molecular markers are beneficial while cost efficient, and whether these markers have any prognostic information about the status of lymphatic spread into the neck.

\section{Summary}

Thyroid nodules are common entities that a thyroid surgeon must evaluate. Nodules are found through physical exam, or incidentally through imaging modalities performed for other reasons. The majority of thyroid nodules are benign, but they warrant surgical excision when they are large enough to be symptomatic or if there is concern for malignancy. Ultrasound is the primary study by which the thyroid gland is imaged. Nodules one centimeter or larger or sonographically suspicious subcentimeter nodules warrant cytologic analysis through fineneedle aspiration biopsy (FNAB) to determine the risk of malignancy. Molecular biomarkers have shown great promise in their ability to detect malignancy in FNAB specimens, and are serving as a powerful adjunct to cytology where they are available. Detecting malignancy preoperatively allows total thyroidectomy in a single operation without the need for frozen section or removal of the thyroid remnant in a second surgery. Cytology and molecular biomarkers are the primary diagnostic modalities a surgeon utilizes to determine the extent of thyroid surgery.

\section{References}

1. Mortensen JD, Woolner LB, Bennett WA. Gross and microscopic findings in clinically normal thyroid glands. J Clin Endocrinol Metab 1955;15(10):1270-80. [PubMed: 13263417]

2. Singer PA. Evaluation and management of the solitary thyroid nodule. Otolaryngol Clin North Am 1996;29(4):577-91. [PubMed: 8844731]

3. Ezzat S, Sarti DA, Cain DR, Braunstein GD. Thyroid incidentalomas. Prevalence by palpation and ultrasonography. Arch Intern Med 1994;154(16):1838-40. [PubMed: 8053752]

4. Papini E, Guglielmi R, Bianchini A, Crescenzi A, Taccogna S, Nardi F, et al. Risk of malignancy in nonpalpable thyroid nodules: predictive value of ultrasound and color-Doppler features. J Clin Endocrinol Metab 2002;87(5):1941-6. [PubMed: 11994321]

5. Nam-Goong IS, Kim HY, Gong G, Lee HK, Hong SJ, Kim WB, et al. Ultrasonography-guided fineneedle aspiration of thyroid incidentaloma: correlation with pathological findings. Clin Endocrinol (Oxf) 2004;60(1):21-8. [PubMed: 14678283]

6. Barroeta JE, Wang H, Shiina N, Gupta PK, Livolsi VA, Baloch ZW. Is fine-needle aspiration (FNA) of multiple thyroid nodules justified? Endocr Pathol 2006;17(1):61-5. [PubMed: 16760581]

7. Frates MC, Benson CB, Doubilet PM, Kunreuther E, Contreras M, Cibas ES, et al. Prevalence and distribution of carcinoma in patients with solitary and multiple thyroid nodules on sonography. J Clin Endocrinol Metab 2006;91(9):3411-7. [PubMed: 16835280]

8. Ferrone S, Marincola FM. Loss of HLA class I antigens by melanoma cells: molecular mechanisms, functional significance and clinical relevance. Immunol Today 1995;16(10):487-94. [PubMed: 7576053]

9. Hegedus L. Clinical practice. The thyroid nodule. N Engl J Med 2004;351(17):1764-71. [PubMed: 15496625]

10. McCoy KL, Jabbour N, Ogilvie JB, Ohori NP, Carty SE, Yim JH. The incidence of cancer and rate of false-negative cytology in thyroid nodules greater than or equal to $4 \mathrm{~cm}$ in size. Surgery $2007 ; 142$ (6):837-44. discussion 844 e1-3. [PubMed: 18063065]

11. Jarlov AE, Nygaard B, Hegedus L, Hartling SG, Hansen JM. Observer variation in the clinical and laboratory evaluation of patients with thyroid dysfunction and goiter. Thyroid 1998;8(5):393-8. [PubMed: 9623729]

12. Raza SN, Shah MD, Palme CE, Hall FT, Eski S, Freeman JL. Risk factors for well-differentiated thyroid carcinoma in patients with thyroid nodular disease. Otolaryngol Head Neck Surg 2008;139 (1):21-6. [PubMed: 18585556] 
13. Hanna BC, Brooker DS. A preliminary study of simple voice assessment in a routine clinical setting to predict vocal cord paralysis after thyroid or parathyroid surgery. Clin Otolaryngol 2008;33(1):636. [PubMed: 18302559]

14. Wong CK, Wheeler MH. Thyroid nodules: rational management. World J Surg 2000;24(8):934-41. [PubMed: 10865037]

15. Elisei R, Bottici V, Luchetti F, Di Coscio G, Romei C, Grasso L, et al. Impact of routine measurement of serum calcitonin on the diagnosis and outcome of medullary thyroid cancer: experience in 10,864 patients with nodular thyroid disorders. J Clin Endocrinol Metab 2004;89(1):163-8. [PubMed: 14715844]

16. Gleich LL, Gluckman JL, Nemunaitis J, Suen JY, Hanna E, Wolf GT, et al. Clinical experience with HLA-B7 plasmid DNA/lipid complex in advanced squamous cell carcinoma of the head and neck. Arch Otolaryngol Head Neck Surg 2001;127(7):775-9. [PubMed: 11448348]

17. Fish SA, Langer JE, Mandel SJ. Sonographic imaging of thyroid nodules and cervical lymph nodes. Endocrinol Metab Clin North Am 2008;37(2):401-17. ix. [PubMed: 18502334]

18. Hegedus L. Thyroid ultrasound. Endocrinol Metab Clin North Am 2001;30(2):339-60. viii-ix. [PubMed: 11444166]

19. Shibuya TY, Kim S, Nguyen K, Parikh P, Wadhwa A, Brockardt C, et al. Covalent linking of proteins and cytokines to suture: enhancing the immune response of head and neck cancer patients. Laryngoscope 2003;113(11):1870-84. [PubMed: 14603040]

20. Cases JA, Surks MI. The changing role of scintigraphy in the evaluation of thyroid nodules. Semin Nucl Med 2000;30(2):81-7. [PubMed: 10787188]

21. Mazzaferri EL. Management of a solitary thyroid nodule. N Engl J Med 1993;328(8):553-9. [PubMed: 8426623]

22. Rohren EM, Turkington TG, Coleman RE. Clinical applications of PET in oncology. Radiology 2004;231(2):305-32. [PubMed: 15044750]

23. Bogsrud TV, Karantanis D, Nathan MA, Mullan BP, Wiseman GA, Collins DA, et al. The value of quantifying 18F-FDG uptake in thyroid nodules found incidentally on whole-body PET-CT. Nucl Med Commun 2007;28(5):373-81. [PubMed: 17414887]

24. Mitchell JC, Grant F, Evenson AR, Parker JA, Hasselgren PO, Parangi S. Preoperative evaluation of thyroid nodules with 18FDG-PET/CT. Surgery 2005;138(6):1166-74. discussion 1174-5. [PubMed: 16360405]

25. de Geus-Oei LF, Pieters GF, Bonenkamp JJ, Mudde AH, Bleeker-Rovers CP, Corstens FH, et al. 18F-FDG PET reduces unnecessary hemithyroidectomies for thyroid nodules with inconclusive cytologic results. J Nucl Med 2006;47(5):770-5. [PubMed: 16644746]

26. Razfar A, Christopoulos A, Lebeau SO, Hodak S, Carty SE, Escott EJ, Branstetter BF, Ferris RL. Clinical Utility of PET-CT in Recurrent Thyroid Carcinoma. Archives of Otolaryngology. 2009 in press.

27. Sidawy MK, Del Vecchio DM, Knoll SM. Fine-needle aspiration of thyroid nodules: correlation between cytology and histology and evaluation of discrepant cases. Cancer 1997;81(4):253-9. [PubMed: 9292740]

28. Danese D, Sciacchitano S, Farsetti A, Andreoli M, Pontecorvi A. Diagnostic accuracy of conventional versus sonography-guided fine-needle aspiration biopsy of thyroid nodules. Thyroid 1998;8(1):1521. [PubMed: 9492148]

29. Baloch ZW, LiVolsi VA, Asa SL, Rosai J, Merino MJ, Randolph G, et al. Diagnostic terminology and morphologic criteria for cytologic diagnosis of thyroid lesions: a synopsis of the National Cancer Institute Thyroid Fine-Needle Aspiration State of the Science Conference. Diagn Cytopathol 2008;36 (6):425-37. [PubMed: 18478609]

30. Chehade JM, Silverberg AB, Kim J, Case C, Mooradian AD. Role of repeated fine-needle aspiration of thyroid nodules with benign cytologic features. Endocr Pract 2001;7(4):237-43. [PubMed: 11497473]

31. Franco C, Martinez V, Allamand JP, Medina F, Glasinovic A, Osorio M, et al. Molecular markers in thyroid fine-needle aspiration biopsy: a prospective study. Appl Immunohistochem Mol Morphol 2009;17(3):211-5. [PubMed: 19384080] 
32. Adeniran AJ, Zhu Z, Gandhi M, Steward DL, Fidler JP, Giordano TJ, et al. Correlation between genetic alterations and microscopic features, clinical manifestations, and prognostic characteristics of thyroid papillary carcinomas. Am J Surg Pathol 2006;30(2):216-22. [PubMed: 16434896]

33. Xing M, Westra WH, Tufano RP, Cohen Y, Rosenbaum E, Rhoden KJ, et al. BRAF mutation predicts a poorer clinical prognosis for papillary thyroid cancer. J Clin Endocrinol Metab 2005;90(12):63739. [PubMed: 16174717]

34. Elisei R, Ugolini C, Viola D, Lupi C, Biagini A, Giannini R, et al. BRAF(V600E) mutation and outcome of patients with papillary thyroid carcinoma: a 15-year median follow-up study. J Clin Endocrinol Metab 2008;93(10):3943-9. [PubMed: 18682506]

35. Nikiforova MN, Lynch RA, Biddinger PW, Alexander EK, Dorn GW 2nd, Tallini G, et al. RAS point mutations and PAX8-PPAR gamma rearrangement in thyroid tumors: evidence for distinct molecular pathways in thyroid follicular carcinoma. J Clin Endocrinol Metab 2003;88(5):2318-26. [PubMed: 12727991]

36. Nikiforov YE, Steward DL, Robinson-Smith TM, Haugen BR, Klopper JP, Zhu Z, et al. Molecular testing for mutations in improving the fine-needle aspiration diagnosis of thyroid nodules. J Clin Endocrinol Metab 2009;94(6):2092-8. [PubMed: 19318445]

37. Chung KW, Yang SK, Lee GK, Kim EY, Kwon S, Lee SH, et al. Detection of BRAFV600E mutation on fine needle aspiration specimens of thyroid nodule refines cyto-pathology diagnosis, especially in BRAF600E mutation-prevalent area. Clin Endocrinol (Oxf) 2006;65(5):660-6. [PubMed: 17054470]

38. Salvatore G, Giannini R, Faviana P, Caleo A, Migliaccio I, Fagin JA, et al. Analysis of BRAF point mutation and RET/PTC rearrangement refines the fine-needle aspiration diagnosis of papillary thyroid carcinoma. J Clin Endocrinol Metab 2004;89(10):5175-80. [PubMed: 15472223]

39. Sapio MR, Posca D, Raggioli A, Guerra A, Marotta V, Deandrea M, et al. Detection of RET/PTC, TRK and BRAF mutations in preoperative diagnosis of thyroid nodules with indeterminate cytological findings. Clin Endocrinol (Oxf) 2007;66(5):678-83. [PubMed: 17381488]

40. Meko JB, Norton JA. Large cystic/solid thyroid nodules: a potential false-negative fine-needle aspiration. Surgery 1995;118(6):996-1003. discussion 1003-4. [PubMed: 7491545]

41. Miller MC, Rubin CJ, Cunnane M, Bibbo M, Miller JL, Keane WM, et al. Intraoperative pathologic examination: cost effectiveness and clinical value in patients with cytologic diagnosis of cellular follicular thyroid lesion. Thyroid 2007;17(6):557-65. [PubMed: 17614777]

42. Richards ML, Chisholm R, Bruder JM, Strodel WE. Is thyroid frozen section too much for too little? Am J Surg 2002;184(6):510-4. discussion 514. [PubMed: 12488150]

43. Cheng MS, Morgan JL, Serpell JW. Does frozen section have a role in the intraoperative management of thyroid nodules? ANZ J Surg 2002;72(8):570-2. [PubMed: 12190731]

44. Cooper DS, Doherty GM, Haugen BR, Kloos RT, Lee SL, Mandel SJ, et al. Management guidelines for patients with thyroid nodules and differentiated thyroid cancer. Thyroid 2006;16(2):109-42.

[PubMed: 16420177] 


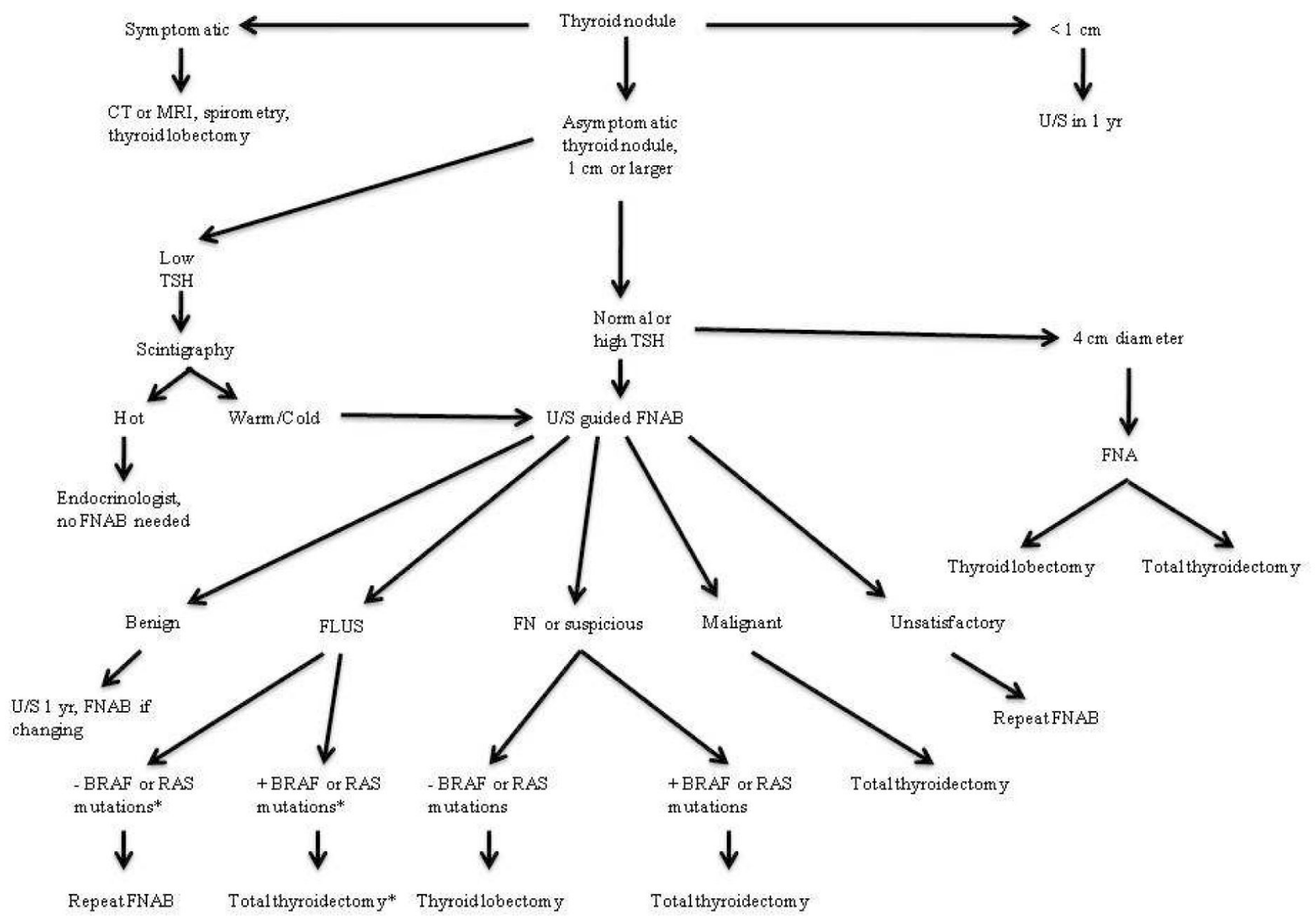

*based on unpublished data from the University of Pittsburgh Medical Center

Figure 1.

Workup of a thyroid nodule 


\section{Table 1}

Reported sensitivities and specificities of sonographic characteristics for detection of thyroid cancer

\begin{tabular}{lcc}
\hline & Median Sensitivity & Median Specificity \\
\hline Microcalcifications & $52 \%$ & $83 \%$ \\
Absence of halo & $66 \%$ & $54 \%$ \\
Irregular margins & $55 \%$ & $79 \%$ \\
Hypoechoic & $81 \%$ & $53 \%$ \\
Increased intranodular flow & $67 \%$ & $81 \%$ \\
\hline
\end{tabular}

Reproduced with modification from (17).

Fish SA, Langer JE, Mandel SJ. Sonographic imaging of thyroid nodules and cervical lymph nodes. Endocrinol Metab Clin North Am 2008;37(2): 401-17, ix 


\section{Table 2}

National Cancer Institute Thyroid Fine-needle Aspiration State of the Science Conference; Bethesda, MD

\begin{tabular}{ll}
\hline Proposed categories & Risk of malignancy \\
\hline Benign & $<1 \%$ \\
Follicular lesion of undetermined significance & $5-10 \%$ \\
Neoplasm (follicular or Oncocytic) & $20-30 \%$ \\
Suspicious for malignancy & $50-75 \%$ \\
Malignant & $100 \%$ \\
Nondiagnostic & N/A \\
\hline
\end{tabular}

Reproduced with modification from (29)

Baloch ZW, LiVolsi VA, Asa SL, Rosai J, Merino MJ, Randolph G, et al. Diagnostic terminology and morphologic criteria for cytologic diagnosis of thyroid lesions: a synopsis of the National Cancer Institute Thyroid Fine-Needle Aspiration State of the Science Conference. Diagn Cytopathol 2008;36(6):425-37 